\title{
In vivo Antimicrobial Activity Assessment of a Cauliflower By-Product Extract Against Salmonella Typhimurium
}

\section{Diana Ibáñez-Peinado ${ }^{1}$, Consuelo Pina-Pérez ${ }^{2}$, Gema García-Carrión ${ }^{1}$, Antonio Martínez ${ }^{1}$ and Dolores Rodrigo ${ }^{1 *}$}

${ }^{1}$ Instituto de Agroquímica y Tecnología de Alimentos (IATA-CSIC), Valencia, Spain, ${ }^{2}$ Faculty of Biological Sciences, University of Valencia, Valencia, Spain

The main objective of this work was to study the antimicrobial effect of a cauliflower by-product infusion into an affordable in vivo model (Caenorhabditis elegans). The infusion demonstrated some protective effect on non-infected and infected worms with Salmonella Typhimurium as indicated by higher survival percentile values $(75,50,25$, and $5 \%$ percentiles) as compared with those from worms unexposed to the infusion. The antimicrobial effect of the infusion was evaluated on Salmonella intestinal colonization of infected worms (24, 48, and $96 \mathrm{~h}$ post-infection). At $96 \mathrm{~h}$ post-infection, the concentration of Salmonella was reduced around 2 log cycles in infected cauliflower treated group $(p<0.05)$ as compared with infected non-cauliflower group. Here we show that cauliflower by-products extend survival and have an antimicrobial effect in an in vivo nematode model, $C$. elegans, as a previous validation step to longer and costlier farm animal studies.

Keywords: agro-industrial waste, by-product, cauliflower, antimicrobial activity, C. elegans, Salmonella Typhimurium

\section{INTRODUCTION}

Some natural antimicrobials by-products from plants (essential oils and plant extracts) have demonstrated their effectiveness against Salmonella Typhimurium in vitro (Sanz-Puig et al., 2015a; Mohamed et al., 2016). It has also been found that many vegetables in the Cruciferae family have antimicrobial properties against several microorganisms of clinical importance. The in vitro antibacterial effect of Brassica oleracea products on several foodborne pathogens was evidenced by Brandi et al. (2006) and Sanz-Puig et al. (2017), between others. Some of the antimicrobial properties of these plant extracts are associated with antioxidant compounds such as polyphenols (Sanz-Puig et al., 2015b; Marchese et al., 2016; Bakari et al., 2018). It is believed that the antibacterial activity of phenolic compounds is due to direct interference with bacterial growth or to inhibition of the production of virulence factors, resulting in attenuated pathogenesis (Ivanova et al., 2013).

Salmonellosis is one of the most recurrent food safety problems in the EU (100,000 cases reported/year, European Food Safety Authority (EFSA)., 2014). It is a zoonotic disease or infection that can be transmitted directly or indirectly between animals and humans. Salmonella spp. are commonly found in the intestines of healthy birds and mammals and, in food, it is most often found in eggs and raw meat from pigs, turkeys, and chickens contaminated during the slaughterhouse process. To reduce the risk of infection, it is important to prevent the disease at the farm. Reduction 
of the microbial load in the intestine of animals prior to slaughter could be a control measure for salmonellosis infections transmitted by food by reducing the level of contamination of flesh at the slaughterhouse.

Before testing the effect of antimicrobials in the intestine of farm animals, which requires resources that are sometimes substantial, some in vivo assays could be carried out in a more affordable system. In this way, the nematode C. elegans can play an interesting role as a live test organism. This organism is an invertebrate hermaphrodite nematode that feeds on bacteria and lives in the soil. Owing to the conservation of many homologous biological processes with mammals, C. elegans has been chosen as a test organism in many studies on the virulence effect of pathogenic bacteria (Kurz and Ewbank, 2000; Jiang and Wang, 2018). In addition, aspects of aging are similar between nematodes and mammals, including humans (Wilson et al., 2006).

The use of by-product extracts or infusions obtained from byproducts offers another interesting way to comply with a circular economy by reducing and revalorizing agro-industrial residuals. Considering these findings, the use of these natural extracts in animal feed could be an alternative, non-curative, control option for the pathogenic bacteria in animal intestines.

The objective of the present work was to study the effect of a by-product infusion from B. oleracea var. botrytis on C. elegans, evaluating the survival of the infected by Salmonella Typhimurium and non-infected nematodes and the survival of Salmonella in the worm's intestine fed with the infusion.

\section{MATERIALS AND METHODS}

\section{Culture of Nematodes and Microbial Strains}

Caenorhabditis elegans strain N2 was provided by the College of Biological Sciences, Minnesota University, USA. For optimal growth of the nematodes, Nematode Growth Medium (NGM) agar was used in medium-size plates $(60 \mathrm{~mm}$ diameter $)$ for general strain maintenance, and larger plates ( $100 \mathrm{~mm}$ diameter) for growing larger quantities of worms, with a bacterial lawn of Escherichia coli strain OP50 (E. coli OP50) at $20^{\circ} \mathrm{C}$ (Stiernagle, 2006). The study was performed with young adult C. elegans (L4 growth stage) that were previously synchronized.

E. coli strain OP50 was grown in Luria-Bertani broth overnight before its inoculation on NGM plates (Roth et al., 1985).

$S$. Typhimurium was provided by the Spanish Type Culture Collection (CECT 443). The Salmonella strain was grown in Tryptic Soy Broth (TSB) (Scharlab Chemie) and incubated for $14 \mathrm{~h}$ at $37^{\circ} \mathrm{C}$ to obtain a stock of cells.

\section{Preparation of Nematode Growth Medium (NGM) Agar With Cauliflower By-Product Infusion}

Cauliflower infusion was made from by-product consisting of dried leaves of $B$. oleracea var. botrytis. These byproducts were provided by TRASA S.L. from agro-industrial primary production.
To prepare a $3 \%(\mathrm{w} / \mathrm{v})$ cauliflower infusion, $0.1 \%$ peptone water was boiled. The by-product was added when the water boiled and it was left infuse for $30 \mathrm{~min}$. After that, the infusion was centrifuged at $6,000 \mathrm{~g}$ for $15 \mathrm{~min}$ at $4^{\circ} \mathrm{C}$. Next, it was vacuum filtered with Whatman filter paper $(90 \mathrm{~mm}$ diameter). Finally, NGM medium with cauliflower infusion was prepared by replacing the distilled water with the infusion that had been obtained.

The concentration of $3 \%(\mathrm{w} / \mathrm{v})$ cauliflower was chosen because it was the maximum that had shown in vitro antimicrobial activity and allowed the growth of $E$. coli OP50.

\section{C. elegans Survival Studies}

For survival studies, uninfected nematodes were distributed on NGM agar with E. coli OP50 lawn plates (N) or on NGM agar with E. coli OP50 lawn supplemented with 3\% cauliflower infusion plates (N_CA).

In the same way, infected nematodes were distributed on NGM agar with E. coli OP50 lawn plates (I) or NGM agar with E. coli OP50 lawn supplemented with $3 \%$ cauliflower by-product infusion plates (I_CA), depending on the survival study.

In all study cases (uninfected and infected nematodes), five repeats were evaluated with 5 plates each. Each plate contained 10 synchronized worms, i.e., 50 nematodes per repeat. The total number of synchronized worms used in the study was 250 for each process.

Live worms on each plate were counted every $48 \mathrm{~h}$ for 21 days.

\section{Salmonella Infection}

For $S$. Typhimurium infection, the nematodes were transferred to plates with NGM agar and Salmonella Typhimurium lawn and kept in contact with the pathogen for $5 \mathrm{~h}$. After that time, they were transferred to the appropriate medium for the survival study (I or I_CA plates, for the media without or with cauliflower, respectively).

\section{Quantification of S. Typhimurium Infection in the Intestine of $C$. elegans}

For the quantification of Salmonella Typhimurium in the digestive tract of the nematode, 5 worms infected with Salmonella Typhimurium were lysed 24,48 , and $96 \mathrm{~h}$ after feeding in the various media already described (I or I_CA plates, for the media without or with cauliflower, respectively). For this purpose, the worms were placed in a plate of NGM medium and were washed twice with $10 \mu \mathrm{l}$ of M9 medium. The five washed worms were transferred to a $1.5 \mathrm{ml}$ Eppendorf containing $1 \mathrm{ml}$ of M9 with 1\% Triton X-100 and five glass beads. Lysis of C. elegans contained in the Eppendorf tubes was performed by mechanical action using a vortex. The concentration of Salmonella $(\mathrm{CFU} / \mathrm{ml})$ in the digestive tract of $C$. elegans was obtained from lysates, which were serially diluted, and incubated in Eosin Methylene Blue agar (EMB agar) at $37^{\circ} \mathrm{C}$ for $48 \mathrm{~h}$. Base dilutions were made from 10 to $10^{-4}$ to achieve a reliable count that established the concentration of Salmonella sp. Presumptive colonies of lactosenegative Salmonella sp. were counted when bacteria showed absence of coloration in this EMB culture medium. The assay plates were prepared in duplicate. 


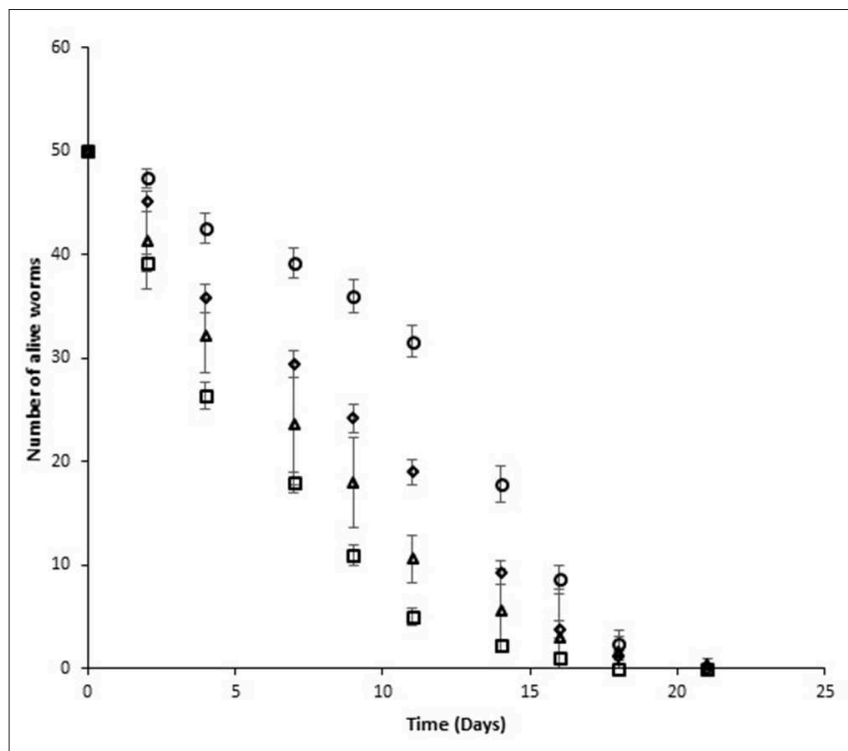

FIGURE 1 | C. elegans survival curves for the various nematode groups considered in the study ( $\left.N: \triangle, N \_C A: \bigcirc, I: \square, I \_C A: \diamond\right)$. Each point represents mean \pm standard deviation (error bars) of five repeat values.

This study was carried out in duplicate with 30 plates, with one synchronized nematode in each plate.

\section{Statistical Analysis}

The analysis of experimental data of microbial counts and survival curves was carried out by using Statgraphics Centurion XVI (Statpoint Technologies, Inc., USA). Kaplan Meyer analysis was performed for survival curves. The statistical significance of the microbial counts was determined by ANOVA.

\section{RESULTS}

\section{Effect of Cauliflower By-Product Extract Infusion on Uninfected C. elegans}

The survival curves for the various nematode groups under study until all the nematodes died are shown in Figure 1, Table S1. As can be seen, from the second day until the end of the study (21 days) the number of live nematodes at each defined length of time was significantly higher for the uninfected nematode group fed with cauliflower extract (N_CA) than for the control $(\mathrm{N})$ group $(p<0.05)$. These findings in the survival curve were patent when the percentiles were analyzed (Table $\mathbf{1}$ ).

Although the number of live nematodes decreased with time until the end of the 21 days, 50 percent of the uninfected worms fed on 3\% cauliflower extract (N_CA) survived for a length of time equal to 12.4 days, whereas in the control group (N) 50 percent of the worms survived for a length of time equal to 6.9 days. The difference in survival between the two groups was still maintained until the fifth percentile, with values of $16.65 \pm$ 3.3 and $17.9 \pm 2.8$ days for the control $(\mathrm{N})$ and cauliflower-fed (N_CA) groups, respectively. Thus, the presence of cauliflower
TABLE 1 | Percentiles of $C$. elegans lifespan for the various nematode groups considered in the study.

\begin{tabular}{lrrrr}
\hline Percentile (\%) & \multicolumn{4}{c}{ Survival time (days, standard deviation) } \\
\cline { 2 - 5 } & \multicolumn{1}{c}{ N } & \multicolumn{1}{c}{ N_CA } & \multicolumn{1}{c}{ I } & \multicolumn{1}{c}{ I_CA } \\
\hline 75 & $3.81 \pm 1.5$ & $7.8 \pm 2.6$ & $2.2 \pm 0.6$ & $3.6 \pm 0.8$ \\
50 & $6.92 \pm 2.0$ & $12.4 \pm 0.9$ & $4.4 \pm 1.8$ & $8.8 \pm 1.8$ \\
25 & $11.52 \pm 2.0$ & $15.1 \pm 1.3$ & $8.8 \pm 1.9$ & $13.0 \pm 1.6$ \\
5 & $16.65 \pm 3.3$ & $17.9 \pm 2.8$ & $13.7 \pm 1.0$ & $17.0 \pm 1.8$ \\
\hline
\end{tabular}

Values represent the survival time (days \pm standard deviation) at the $75,50,25$, and $5 \%$ percentiles in each study treatment.

in the feed medium appears to decrease the death rate of the nematodes at each time interval tested.

\section{Effect of Infection With Salmonella Typhimurium on C. elegans}

As shown in Figure 1, infection produced a statistically significant $(p<0.05)$ reduction in live nematodes for a defined length of time in the I group in comparison with the uninfected $\mathrm{N}$ control group, both fed on standard Nematode Growth Medium. Percentile analysis (Table 1) indicated the difference for the 50th percentile between the uninfected group (N) (6.9 \pm 2.0 days) and the infected group (I) (4.4 \pm 1.8 days). This difference in lifespan between the $\mathrm{N}$ and I groups was also observed for the 75, 25, and 5th percentiles, where the worms were very close to the limit of their lifespan. These results indicate that Salmonella infection affected the survival of C. elegans.

\section{Effect of Cauliflower By-Product Extract Infusion on C. elegans Infected by Salmonella Typhimurium}

When infected worms were fed on a medium containing cauliflower by-product infusion (I_CA group), differences in the survival curve were patent compared with that of the infected group fed without the infusion (I) and the control group (N) (Figure 1). A statistically significant $(p<0.05)$ increase in survival after defined periods of time was observed for the I_CA group, although the increase was lower than that observed in the uninfected group fed with cauliflower by-product infusion (N_CA). This increase in survival was reflected in all percentiles, as can be seen in Table 1. According to this table, 50 percent of the worms survived for a period of time equal to $8.8 \pm 1.8$ days in the I_CA group, while in the I group they survived for a length of time equal to $4.4 \pm 1.8$ days. Again, the cauliflower extract appears to have had a beneficial effect on C. elegans, extending the survival for a certain length of time. According to these results, it is important to know how Salmonella evolves in the worm's intestine after infection and to try to determine whether the extract could exert its antimicrobial effect inside the nematode's intestine or not, before considering its use as a control measure before animals are subjected to the slaughterhouse process. 


\section{Quantification and Evolution of $S$. Typhimurium Infection in the Intestine of C. elegans}

The evolution of the Salmonella counts in the nematode's intestine expressed as $\log (\mathrm{N} / \mathrm{N} 0)$ for the two groups, infected (I) and infected fed with cauliflower extract (I_CA), can be seen in Figure 2, Table S2.

It was observed that Salmonella grew until the fraction reached $1.25 \log$ in the I group $24 \mathrm{~h}$ after infection, while for the I_CA Salmonella counts increased only 0.5 log cycles, being significant differences $(p \leq 0.05)$ between both populations for the same period of time. This means that an increase in Salmonella survival in the C. elegans digestive system took place during the first $24 \mathrm{~h}$ post-infection period, irrespective of the group considered, but some control of Salmonella growth was exerted by the cauliflower extract that it only increased $0.5 \mathrm{log}$ cycles. Salmonella growth decreased at $48 \mathrm{~h}$ after infection and remained stable until $96 \mathrm{~h}$ after infection in worms not fed with cauliflower extract. When worms infected with Salmonella were fed with cauliflower extract, death of Salmonella was observed at 48 and $96 \mathrm{~h}$ and counts were significantly lower $(p \leq 0.05)$ than in nematodes infected but not fed with cauliflower extract (Figure 2). Cauliflower extract acted as an antimicrobial in the nematode's intestine, reducing the microbial survival fraction by about two log cycles.

According to these results, it is possible to say that the presence of cauliflower by-product infusion in NGM agar appears to control infection of the C. elegans digestive tract by S. Typhimurium.

\section{DISCUSSION}

It has been reported that the lifespan of $C$. elegans is related with genetic and environmental factors, such as temperature, food

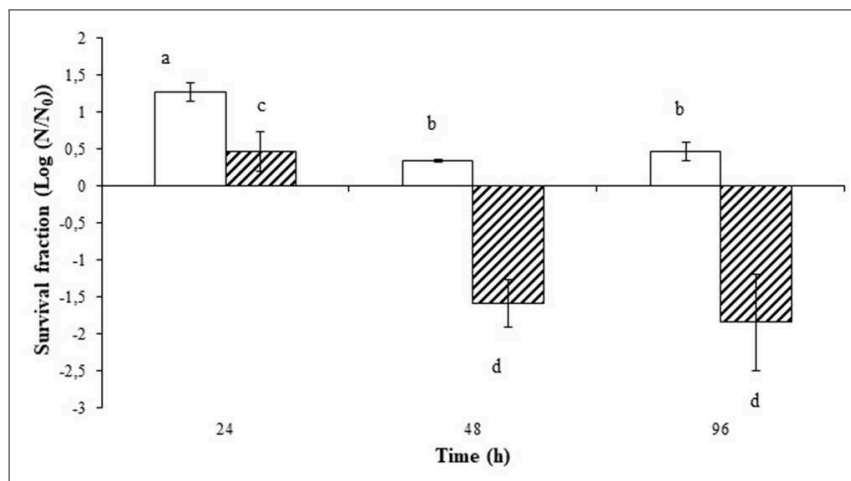

FIGURE 2 | Evolution of the microbial load of Salmonella in the intestine of $C$. elegans at 24, 48, and $96 \mathrm{~h}$ post-infection fed (stripped bar) and not fed (blank bar) with cauliflower extract. Survival of Salmonella Typhimurium in the intestine of $C$. elegans is expressed as survival fraction of Salmonella cells $(\mathrm{CFU} / \mathrm{mL})$ in the intestine of $C$. elegans (Log (N/NO)) at 24, 48, and $96 \mathrm{~h}$ post-infection fed and not fed with cauliflower extract. Different letters indicate significant differences in survival fractions $(p \leq 0.05)$ and error bars represent standard deviation. availability and composition (Blumenthal and Steward, 1997; Uno and Nishida, 2016). According to Sanz-Puig et al. (2015a) and Vieira (2013), cauliflower by-product infusion provides bioactive compounds such as polyphenols. It has been found that polyphenols contained in hydrophilic extracts of Brassica species are responsible for $80-95 \%$ of their total antioxidant capacity (Kurilich et al., 2002; Xianli et al., 2004). According to different authors (Kampkötter et al., 2008; Saul et al., 2011; Surco-Laos et al., 2011; Grünz et al., 2012; Kim et al., 2014), cauliflower polyphenols such as gallic acid, catechin, protocatechuic acid, quercetin and kaempferol prolonged the lifespan of C. elegans between 5.6 and 15\% and produced some stress protection. However, other studies reported protection against thermal stress but no protection against acute oxidative stress (Wilson et al., 2006) or extended C. elegans lifespan (Chen et al., 2013).

Studies with other compounds rich in polyphenols showed that they increased the lifespan and thermotolerance of C. elegans (Wilson et al., 2006; Pallauf et al., 2017). After studying the effect of an herbal mixture on C. elegans, Moriwaki et al. (2013) concluded that the herbal mixture prolonged its lifespan, delayed aging, and also suppressed oxidation of protein cells in the nematode. However, it appears that the longevity of the C. elegans mev-1 (kn1) mutant produced by gallic acid, which is present in cauliflower, was not due to its antioxidant capacity but to its antimicrobial properties (Saul et al., 2011). All these findings may help to explain why the cauliflower extract infusion clearly reflected a positive influence on the C. elegans lifespan of N_CA and I_CA compared with the $\mathrm{N}$ and I control groups.

At the same time, it has been demonstrated that $S$. Typhimurium shortened the survival of C. elegans (Aballay et al., 2000; Labrousse et al., 2000; Sem and Rhen, 2012). Fifty percent of L4-stage worms were alive about 9 days after being exposed to $S$. Typhimurium strain 12023 for $8 \mathrm{~h}$ and then returned to an E. coli OP50 lawn as feeding material (Labrousse et al., 2000). Aballay et al. (2000) used 1-day adult nematodes exposed to $S$. Typhimurium for their study and found that $50 \%$ of the nematodes were dead at 5.1 days when exposed to $S$. Typhimurium SL 1344 or 4.8 days when infected by $S$. Typhimurium 14028. In our study, 50\% of the worms survived for 4.4 days in the case of nematodes infected by $S$. Typhimurium (CECT 443) without cauliflower extract exposure. These results are in agreement with the above-mentioned studies, although some authors have indicated that factors such as difference in culture temperature, inter-individual differences, and/or use of different Salmonella strains could affect survival of the nematode (Blumenthal and Steward, 1997). The virulence mechanism may be due to intracellular infection in the host, although Sem and Rhen (2012) described a new form of virulence that depends on the ability to induce overwhelming oxidative stress in the host through redox activity of bacterial thioredoxin 1 without intracellular invasion.

In the present work, a similar protective effect of the cauliflower extract on the infected nematodes was observed. C. elegans can use various strategies against $S$. Typhimurium infection (Alegado and Tan, 2008; Sem and Rhen, 2012; Curt et al., 2014). One defensive mechanism of $C$. elegans against this 
pathogen is production of reactive oxygen species (ROS) while inducing an oxidative stress response that depends on DAF-16, a transcriptional factor (Chávez et al., 2007). Sem and Rhen (2012) indicated that the presence of $50 \mathrm{mM}$ of ascorbic acid reduced the ROS response and significantly increased the lifespan of nematodes infected with $S$. Typhimurium by 2 days at $50 \%$ survival time, compared to the uninfected group. Vayndorf et al. (2013) noticed increased resistance to Pseudomonas aeruginosa in C. elegans pre-treated with whole apple extracts (2 days pretreatment) as well as greater lifespan in a dose-dependent manner compared with infected non-pre-treated worms. They suggested that the pre-treatment with apple extract produced an increase in survival of up to $35.2 \%$ in infected worms, and also that the apple extract enhanced the nematode immune response.

In the present study, the presence of cauliflower extract extended survival by 4 days in infected nematodes at $50 \%$ survival time. This result could indicate that the presence of the cauliflower extract would produce the same effect as vitamin C in reducing the ROS response, or maybe an enhancement of the nematode immune response. It is necessary to take into account the fact that polyphenols are one of the main groups of bioactive components in cruciferous vegetables (Soengas et al., 2011). They have been related to antioxidant properties in C. elegans, inducing resistance to oxidative stress and delaying aging (Wu et al., 2002; Cañuelo et al., 2012).

In recent years, Salmonella infection has reached dramatic levels and has become a challenge in the food sector. The use of antibiotics worldwide has resulted in an increase in antibiotic resistance; consequently, new antimicrobials are necessary to avoid resistance problems with antibiotics used in human therapy. Researchers have focused efforts on the therapeutic activities of natural products from plants. There are many plant essential oils and other products from plants that can be used to control bacteria, including Salmonella (Bajpai et al., 2012). Essential oils added to feed or water have been used to control fecal excretion of Salmonella, with promising results (Borsoi et al., 2011). The authors just cited, used live animals for their trials. However, there are no studies in which cauliflower extract has been used to control Salmonella in the intestine of living animals. The use of live animals for trials can be expensive, so to test the effect of natural antimicrobials from plants in the intestine of infected living beings such as the C. elegans nematode, can be useful as a living test organism before performing field tests. The results of the present study indicate that Salmonella can infect the intestine of C. elegans. Aballay et al. (2000) reported $S$. Typhimurium and E. coli bacteria counts (log CFU/worm) in C. elegans intestine during a period of 5 days. At day 1, intestinal Salmonella grew by $\sim 1.5 \log$ cycles. The pathogenic bacteria counts almost doubled on the second day, and they seemed to stabilize on the third day, when a $3.5 \mathrm{log}$ cycle growth was achieved. In agreement with those findings, in the present work, infected worms showed around a $1.25 \mathrm{log}$ increase in Salmonella cells at day 1; however, in contrast with the results of Aballay et al. (2000), the Salmonella cells decreased by $\sim 1 \log$ cycle $48 \mathrm{~h}$ after infection, with a nonsignificant increase $96 \mathrm{~h}$ after pathogen exposure. The differences encountered in the two studies for untreated infected nematodes at $48 \mathrm{~h}$ and $96 \mathrm{~h}$ post-infection may have been due to the different $S$. Typhimurium strains used in the two studies or other factors.

Marsh et al. (2011) indicated approximate counts of $10^{4} \mathrm{CFU}$ of S. Typhimurium strain L1019 (a GFP-expressing derivative of SL1344) in every L4-stage C. elegans (CFU/worm) at day 1 post-infection. This datum is in accordance with the mean $S$. Typhimurium cell counts $(2.97 \times 104 \mathrm{CFU} /$ worm $)$ found in the present study. However, although Marsh et al. (2011) showed a rise in pathogen concentration to $\sim 10^{7} \mathrm{CFU} /$ worm at day 2 , our results demonstrated a mean CFU/worm decrease to 1.71 $\times 10^{3} \mathrm{CFU} /$ worm. Interestingly, both studies show a similar concentration of Salmonella cells around $10^{3}-10^{4} \mathrm{CFU} /$ worm at day 4. Consequently, from the results presented, it seems that C. elegans can be used to test the efficacy of cauliflower extract in controlling Salmonella in infected nematodes.

\section{CONCLUSIONS}

In conclusion it can be said that cauliflower extract exerts a protective action against aging in uninfected worms, probably owing to an antioxidant activity of the compounds in the extract. This protective effect was also shown in Salmonella-infected worms. Results at the 2 nd and 4 th days post-infection showed a positive effect of cauliflower treatment in lifespan extension related with a nearly $2 \log$ cycle reduction in Salmonella cells at $48 \mathrm{~h}$ and even at $96 \mathrm{~h}$ after infection with the pathogen. Therefore, an interesting feature demonstrated in this study is the effect of cauliflower extract as feed material in controlling Salmonella in the worm intestine by reducing the microbial load after $96 \mathrm{~h}$. Nevertheless, more information is needed on possible pathogen resistance to this natural antimicrobial in relation to time.

In order to optimize the incorporation of this vegetable extract with antimicrobial properties, these findings should be corroborated and completed with experimental studies in farm animals, adapting it to the necessities of each animal species. The use of agro-industrial waste to obtain the vegetable extracts contributes to sustainable agriculture development as well as a possible economic revalorization of these residues.

\section{DATA AVAILABILITY STATEMENT}

All datasets generated for this study are included in the article/Supplementary Material.

\section{AUTHOR CONTRIBUTIONS}

DR: conceptualization and experimental design. AM: writing. GG-C: experimental analysis. DI-P: experimental and data analysis. CP-P: paper supervision.

\section{FUNDING}

This work was supported by funds provided by the Spanish Ministry of Science, Innovation and Universities 
(AGL2017-86840-C2-2-R), and with FEDER funds from EU. We acknowledge support of the publication fee by the CSIC Open Access Publication Support Initiative through its Unit of Information Resources for Research (URICI).

\section{REFERENCES}

Aballay, A., Yorgey, P., and Ausubel, F. M. (2000). Salmonella Typhimurium proliferates and establishes a persistent infection in the intestine of Caenorhabditis elegans. Curr. Biol. 10, 1539-1542. doi: 10.1016/s0960-9822(00)00830-7

Alegado, R. A., and Tan, M. W. (2008). Resistance to antimicrobial peptides contributes to persistence of Salmonella Typhimurium in the C. elegans intestine. Cell. Microbiol. 10, 1259-1273. doi: 10.1111/j.1462-5822.2008.01124.x

Bajpai, V. K., Baek, K. H., and Kang, S. C. (2012). Control of Salmonella in foods by using essential oils: a review. Food Res. Int. 45, 722-734. doi: 10.1016/j.foodres.2011.04.052

Bakari, S., Hajlaoui, H., Daoud, A., Mighri, H., Maria Ross-Garcia, J., Gharsallah, N., et al. (2018). Phytochemicals, antioxidant and antimicrobial potentials and LC-MS analysis of hydroalcoholic extracts of leaves and flowers of Erodium glaucophyllum collected from Tunisian Sahara. Food Sci. Technol. 38, 310-317. doi: 10.1590/fst.04517

Blumenthal, T., and Steward, K. (1997). "RNA processing and gene structure," in C. elegans II. 2nd Edn, eds D. L. Riddle, T. Blumenthal, B. J. Meyer, and J. R. Priess (New York, NY: Cold Spring Harbor), 117-145.

Borsoi, A., Santos, L. R., Diniz, G. S., Salle, C. T. P. C., Moraes, H. L. S., and Nascimento, V. P. (2011). Salmonella fecal excretion control in broiler chickens by organic acids and essential oils blend feed added. Brazil. J. Poultry Sci. 13, 65-69. doi: 10.1590/S1516-635X2011000100010

Brandi, G., Amagliani, G., Schiavano, G. F., De Santi, M., and Sisti, M. (2006). Activity of Brassica oleracea leaf juice on foodborne pathogenic bacteria. J. Food Protect. 69, 2274-2279. doi: 10.4315/0362-028x-69.9.2274

Cañuelo, A., Gilbert-Lopez, B., Pacheco-Linan, P., Martinez-Lara, E., Siles, E., and Miranda-Vizuete, A. (2012). Tyrosol, a main phenol present in extra virgin olive oil, increases lifespan and stress resistance in Caenorhabditis elegans. Mech. Age. Dev. 133, 563-574. doi: 10.1016/j.mad.2012.07.004

Chávez, V., Mohri-Shiomi, A., Maadani, A., Vega, L. A., and Garsin, D. A. (2007). Oxidative stress enzymes are required for DAF-16-mediated immunity due to generation of reactive oxygen species by Caenorhabditis elegans. Genetics 176, 1567-1577. doi: 10.1534/genetics.107.072587

Chen, W., Rezaizadehnajafi, L., and Wink, M. (2013). Influence of resveratrol on oxidative stress resistance and life span in Caenorhabditis elegans. J. Pharm. Pharmacol. 65, 682-688. doi: 10.1111/jphp.12023

Curt, A., Zhang, J., Minnerly, J., and Jia, K. (2014). Intestinal autophagy activity is essential for host defense against Salmonella Typhimurium infection in Caenorhabditis elegans. Dev. Comparat. Immunol. 45, 214-218. doi: 10.1016/j.dci.2014.03.009

European Food Safety Authority (EFSA). (2014). EFSA Explains Zoonotic Diseases: Salmonella. Available online at: https://www.efsa.europa.eu/sites/default/ files/corporate_publications/files/factsheetsalmonella.pdf (accessed January 28, 2020).

Grünz, G., Haas, K., Soukup, S., Klingenspor, M., Kulling, S. E., Daniel, H., et al. (2012). Structural features and bioavailability of four flavonoids and their implications for lifespan-extending and antioxidant actions in C. elegans. Mech. Age. Dev. 133, 1-10. doi: 10.1016/j.mad.2011.11.005

Ivanova, K., Fernandes, M., and Tzanov, T. (2013). "Current advances on bacterial pathogenesis inhibition and treatment strategies," in Microbial Pathogens and Strategies for Combating Them: Science, Technology, and Education, ed A. Méndez-Vilas (Badajoz: Formatex Research Center), 322-336.

Jiang, H., and Wang, D. (2018). The microbial zoo in the C. elegans intestine: bacteria, fungi, and viruses. Viruses Basel 10:85. doi: 10.3390/v10020085

Kampkötter, A., Timpel, C., Zurawski, R. F., Ruhl, S., Chovolou, Y., Proksch, P., et al. (2008). Increase of stress resistance and lifespan of Caenorhabditis elegans

\section{SUPPLEMENTARY MATERIAL}

The Supplementary Material for this article can be found online at: https://www.frontiersin.org/articles/10.3389/fsufs. 2020.00008/full\#supplementary-material

by quercetin. Comp. Biochem. Physiol. B Biochem. Mol. Biol. 149, 314-323. doi: $10.1016 /$ j.cbpb.2007.10.004

Kim, Y. S., Seo, H. W., Lee, M. H., Kim, D. K., Jeon, H., and Cha, D. S. (2014). Protocatechuic acid extends lifespan and increases stress resistance in Caenorhabditis elegans. Archiv. Pharm. Res. 37, 245-252. doi: 10.1007/s12272-013-0183-6

Kurilich, A. C., Jeffery, E. H., Juvik, J. A., Wallig, M. A., and Klein, B. P. (2002). Antioxidant capacity of different broccoli (Brassica oleracea) genotypes using the oxygen radical absorbance capacity (ORAC) assay. J. Agri. Food Chem. 50, 5053-5057. doi: 10.1021/jf025535l

Kurz, C. L., and Ewbank, J. J. (2000). Caenorhabditis elegans for the study of host-pathogen interactions. Trends Microbiol. 8, 142-144. doi: 10.1016/s0966-842x(99)01691-1

Labrousse, A., Chauvet, S., Couillault, C., Kurz, C. L., and Ewbank, J. J. (2000). Caenorhabditis elegans is a model host for Salmonella Typhimurium. Curr. Biol. 10, 1543-1545. doi: 10.1016/s0960-9822(00)00833-2

Marchese, A., Orhan, I. E., Daglia, M., Barbieri, R., Di Lorenzo, A., Nabavi, S. F., et al. (2016). Antibacterial and antifungal activities of thymol: a brief review of the literature. Food Chem. 210, 402-414. doi: 10.1016/j.foodchem.2016. 04.111

Marsh, E. K., van den Berg, M. C. W., and May, R. C. (2011). A two-gene balance regulates Salmonella Typhimurium tolerance in the nematode Caenorhabditis elegans. PLoS ONE 6:e16839. doi: 10.1371/journal.pone.0016839

Mohamed, H., Gaafar, A., and Soliman, A. (2016). Antimicrobial activities of essential oil of eight plant species from different families against some pathogenic microorganisms. Res. J. Microbiol. 11, 28-34. doi: 10.3923/ jm.2016.28.34

Moriwaki, T., Kato, S., Kato, Y., Hosoki, A., and Zhang-Akiyama, Q. M. (2013). Extension of lifespan and protection against oxidative stress by an antioxidant herb mixture complex (KPG-7) in Caenorhabditis elegans. J. Clin. Biochem. Nutr. 53, 81-88. doi: 10.3164/jcbn.13-11

Pallauf, K., Duckstein, N., and Rimbach, G. (2017). A literature review of flavonoids and lifespan in model organisms. Proc. Nutr. Soc. 76, 145-162. doi: $10.1017 /$ S0029665116000720

Roth, R. I., Owen, R. L., Keren, D. F., and Volberding, P. A. (1985). Intestinal infection with Mycobacterium-avium in acquired immune-deficiency syndrome (AIDS) - histological and clinical comparison with whipples disease. Digest. Dis. Sci. 30, 497-504. doi: 10.1007/BF01318186

Sanz-Puig, M., Lazaro, E., Armero, C., Alvares, D., Martínez, A., and Rodrigo, D. (2017). S. Typhimurium virulence changes caused by exposure to different nonthermal preservation treatments using C. elegans. Int. J. Food Microbiol. 262, 49-54. doi: 10.1016/j.ijfoodmicro.2017.09.006

Sanz-Puig, M., Pina-Pérez, M. C., Criado, M. N., Rodrigo, D., and MartínezLópez, A. (2015a). Antimicrobial potential of cauliflower, broccoli, and okara byproducts against foodborne bacteria. Foodborne Pathogens Dis. 12, 39-46. doi: 10.1089/fpd.2014.1801

Sanz-Puig, M., Pina-Pérez, M. C., Saenz Gomez, J., Marañón, I., Rodrigo, D., Martínez, A. (2015b). Effect of polyphenol content on the antimicrobial activity of natural extracts from agroindustrial by-products. J. Food Safety Food Qual. 66, 4-9. doi: 10.2376/0003-925X-66-4

Saul, N., Pietsch, K., Stürzenbaum, S. R., Menze, R., and Steinberg, C. E. W. (2011). Diversity of polyphenol action in Caenorhabditis elegans: between toxicity and longevity. J. Nat. Prod. 74, 1713-1720. doi: 10.1021/np200011a

Sem, X., and Rhen, M. (2012). Pathogenicity of Salmonella enterica in Caenorhabditis elegans relies on disseminated oxidative stress in the infected host. PLoS ONE 7:e45417. doi: 10.1371/journal.pone.0045417

Soengas, P., Sotelo, T., Velasco, P., and Cartea, M. E. (2011). Antioxidant properties of Brassica vegetables. Funct. Plant Sci. Biotechnol. 
5, 43-55. Available online at: https://pdfs.semanticscholar.org/14af/ a996fd8e8609f9209e51ab0ffe4d9722d25a.pdf

Stiernagle, T. (2006). Maintenance of C. elegans. WormBook. Available online at: http://wormbook.org/chapters/www_strainmaintain/strainmaintain.html (accessed 10 October, 2019). doi: 10.1895/wormbook.1.101.1

Surco-Laos, F., Cabello, J., Gomez-Orte, E., Gonzalez-Manzano, S., GonzalezParamas, A. M., Santos-Buelga, C., et al. (2011). Effects of O-methylated metabolites of quercetin on oxidative stress, thermotolerance, lifespan, and bioavailability on Caenorhabditis elegans. Food Func. 2, 445-456. doi: $10.1039 /$ clfo10049a

Uno, M., and Nishida, E. (2016). Lifespan-regulating genes in C. elegans. NPJ Aging Mech. Dis. 2:16010. doi: 10.1038/npjamd.2016.10

Vayndorf, E. M., Lee, S. S., and Liu, R. H. (2013). Whole apple extracts increase lifespan, healthspan, and resistance to stress in Caenorhabditis elegans. J. Func. Foods 5, 1235-1243. doi: 10.1016/j.jff.2013. 04.006

Vieira, P. M. (2013). Avaliação da composição química, dos compostos bioativos e da atividade antioxidante em seis espécies de flores comestiveis Tese (doutorado). Universidade Estadual Paulista Júlio de Mesquita Filho, Faculdade de Ciências Farmacêuticas, 102f. Available online at: http://hdl.handle.net/11449/100866

Wilson, M. A., Shukitt-Hale, B., Kalt, W., Ingram, D. K., Joseph, J. A., and Wolkow, C. A. (2006). Blueberry polyphenols increase lifespan and thermotolerance in Caenorhabditis elegans. Aging Cell 5, 59-68. doi: 10.1111/j.1474-9726.2006.00192.x

Wu, Z. X., Smith, J. V., Paramasivam, V., Butko, P., Khan, I., Cypser, J. R., et al. (2002). Ginkgo biloba extract EGb 761 increases stress resistance and extends life span of Caenorhabditis elegans. Cell. Mol. Biol. 48, 725-731.

Xianli, W., Beecher, G. R., Holden, J. M., Haytowitz, D. B., Gebhardt, S. E., and Prior, R. L. (2004). Lipophilic and hydrophilic antioxidant capacities of common foods in the United States. J. Agri. Food Chem. 52, 4026-4037. doi: 10.1021/jf049696w

Conflict of Interest: The authors declare that the research was conducted in the absence of any commercial or financial relationships that could be construed as a potential conflict of interest.

Copyright (c) 2020 Ibáñez-Peinado, Pina-Pérez, García-Carrión, Martínez and Rodrigo. This is an open-access article distributed under the terms of the Creative Commons Attribution License (CC BY). The use, distribution or reproduction in other forums is permitted, provided the original author(s) and the copyright owner(s) are credited and that the original publication in this journal is cited, in accordance with accepted academic practice. No use, distribution or reproduction is permitted which does not comply with these terms. 